\title{
Geociências
}

\section{Vertedores portáteis em microbacias de drenagem}

\section{(Portable weirs in catchments)}

\author{
Fernanda Martineli Costa \\ Mestre (Engenharia Geológica) \\ Dep. de Geologia da Univ. Federal de Ouro Preto - UFOP/EM \\ E-mail:femartineli@yahoo.com.br \\ Luis de Almeida Prado Bacellar \\ Prof. Dr. , Dep. de Geologia da Univ. Federal de Ouro Preto - UFOP/EM \\ E-mail: bacellar@degeo.ufop.br \\ Eder Fonseca Silva \\ Graduando (Engenharia Geológica) \\ Dep. de Geologia da Univ. Federal de Ouro Preto - UFOP/EM \\ E-mail: eder.silva@geoexplore.com.br
}

\section{Resumo}

A necessidade crescente de conhecimento das condições hídricas em pequenas bacias exige técnicas de pesquisa mais práticas e aprimoradas. A vazão é fundamental em estudos hidrológico/ hidrogeológicos e pode ser determinada por vários métodos. Nesse artigo, procura-se analisar a técnica dos vertedores portáteis, uma alternativa de determinação de pequenas vazões, ainda pouca conhecida em âmbito nacional. Para tanto, foram tomadas, manualmente, duas a três medidas diárias de vazão em dez microbacias de drenagem localizadas na bacia do rio Maracujá, afluente do alto rio das Velhas, Estado de Minas Gerais. Foram utilizados vertedores dos tipos triangular, retangular e trapezoidal Cipoletti, construídos com chapas de aço galvanizado de 4 a $6 \mathrm{~mm}$ de espessura. Os resultados mostraram tratar-se de técnica confiável, prática e econômica de medir a vazão. Embora os picos de vazão nem sempre tenham sido registrados, seja pelo transbordamento do vertedor, como pelo intervalo de leitura longo, foi sempre possível caracterizar o período de recessão. Assim, pode-se determinar o fluxo de base, o coeficiente de recessão e outros índices hídricos aplicáveis em estudos indiretos de caracterização hidrogeológica.

Palavras-chave: Hidrogeologia, vertedor portátil, vazão, microbacia, fluxo de base.

\begin{abstract}
The increasing need for the characterization of hydrological conditions of catchments demands better and more practical research techniques. The streamflow characterization is fundamental for hydrological/ hydrogeological studies and it can be determined by several methods. This paper intends to analyze the portable weir technique, an alternative methodology for low flow determination, still relatively unknown in Brazil. Two to three streamflow measurements a day were manually taken in ten catchments of the Maracujá basin, a tributary of the Alto Rio das Velhas river in the State of Minas Gerais. Three kinds of weir were used: triangular, rectangular and trapezoidal Cipoletti, all of them constructed with 4-6 mm thick galvanized iron plate. The results showed that this is a practical, reliable and economic technique of measuring low flows. Even though the peak flows were occasionally not recorded, either because of the weir overflow or because of the long recording period. The recession period was always well recorded, allowing the determination of the baseflow, the recession coefficient and other hydrological indices, which are useful in the indirect method of hydrogeological characterization.
\end{abstract}

Keywords: Hydrogeology, portable weir, stream flow, catchment; baseflow. 


\section{Introdução}

O conhecimento das condições dos fluxos é uma ferramenta primordial no gerenciamento dos recursos hídricos em bacias hidrográficas, gerenciamento este reconhecidamente necessário frente ao cenário atual de degradação das águas e à necessidade crescente de novas fontes de abastecimento.

A determinação da vazão consiste em uma etapa fundamental nesse processo de caracterização das condições hidrológicas e na avaliação da disponibilidade hídrica de uma bacia, existindo várias técnicas para obtê-la (e.g. Custodio \& Llamas, 1976; Rantz, 1982; ABNT, 1995; Porto, 2001). Contudo, quanto maior a acurácia da técnica, mais dispendiosa e maior a necessidade de recursos técnicos, o que justifica, em parte, o fato de muitas bacias hidrográficas não serem monitoradas continuamente e não terem suas condições hídricas ainda claramente definidas.

Nesse contexto, métodos mais simples e menos onerosos, mas que forneçam dados igualmente confiáveis e aplicáveis em um amplo intervalo de situações, tornam-se extremamente relevantes, já que podem suprir a necessidade de dados e contribuir para o conhecimento, ainda que incipiente, dos regimes hídricos locais.

O presente trabalho discute uma alternativa simples, prática e viável técnica e economicamente de determinação de pequenas vazões. Trata-se de vertedores portáteis, semelhantes aos sugeridos pelo serviço geológico americano - USGS (Rantz, 1982). Correspondem a um meio de aquisição de dados de vazão que pode ser utilizado na estimativa do fluxo de base, ou seja, da componente da vazão proveniente do fluxo subterrâneo, assim como no cálculo do coeficiente de recessão (taxa de decaimento do fluxo de base) e outros índices hídricos utilizados em estudos indiretos de caracterização hidrogeológica.

Tais vertedores foram instalados em dez microbacias de drenagem (Figura 1) com características físicas predefinidas (nomeadas de B1 a B8.1 conforme foram sendo definidas e instrumentadas) durante um ano hidrológico, o que possibilitou a análise de sua aplicabilidade. Considerando que essas bacias possuem áreas relativamente pequenas (média de $1 \mathrm{~km}^{2}$ ), com deflúvios da ordem de menos de 1L/s até valores máximos de aproximadamente 70L/s e ponderando ainda as limitações e vantagens de cada método de determinação da vazão (Neves, 1982; Netto \& Alvarez, 1988; Porto 2001), concluiu-se que o uso de vertedores seria adequado. Buscando uma maior praticidade e custos reduzidos, optou-se, então, pelos vertedores portáteis. Ressalta-se, porém, que, embora fossem portáteis, os vertedores utilizados, nessa pesquisa, permaneceram no mesmo local durante todo o monitoramento (Costa \& Bacellar, 2003; Costa, 2005).

As microbacias localizam-se na bacia do rio Maracujá, afluente esquerdo do alto rio das Velhas (bacia do rio São Francisco) (Figura 1). Geologicamente, situam-se na região central do Quadrilátero Ferrífero, estando estruturadas em rochas graníticas e gnáissicas do embasamento cristalino (Complexo Metamórfico Bação), sendo duas localizadas imediatamente ao sul, em rochas metassedimentares supracrustais (Supergrupo Minas).

\section{Vertedores portáteis}

Vertedor é definido, basicamente, como uma barreira inserida perpendicularmente ao fluxo, que passa, então, a verter através de uma abertura de forma geométrica definida na parte superior dessa barreira. A altura da lâmina d'água nessa abertura, conhecida como carga (h), é, então, utilizada em fórmulas específicas, que fornecem o valor da vazão (e.g. Custodio \& Llamas, 1976; Porto, 2001).

Os vertedores portáteis utilizados constituem-se chapas de aço galvanizado de 4 a $6 \mathrm{~mm}$ de espessura, sendo, portanto, de parede delgada. Foram projetados vertedores retangulares, trapezoidais Cipoletti e triangulares, conforme as condições específicas de cada microbacia, em especial, a amplitude da vazão prevista, sendo todos de lâmina livre e com contração lateral (Figura 2). A chapa foi cravada diretamente nas margens e fundo do canal, tendo, para isso, bordas laterais e inferiores prolongadas e afinadas. Eventualmente foi necessário retirar pedregulhos ou raízes maiores que dificultavam a instalação. Na soleira, foi feito um chanfro de $45^{\circ}$, para facilitar a queda livre da lâmina d'água. Ainda em campo, foram certificados, por meio de

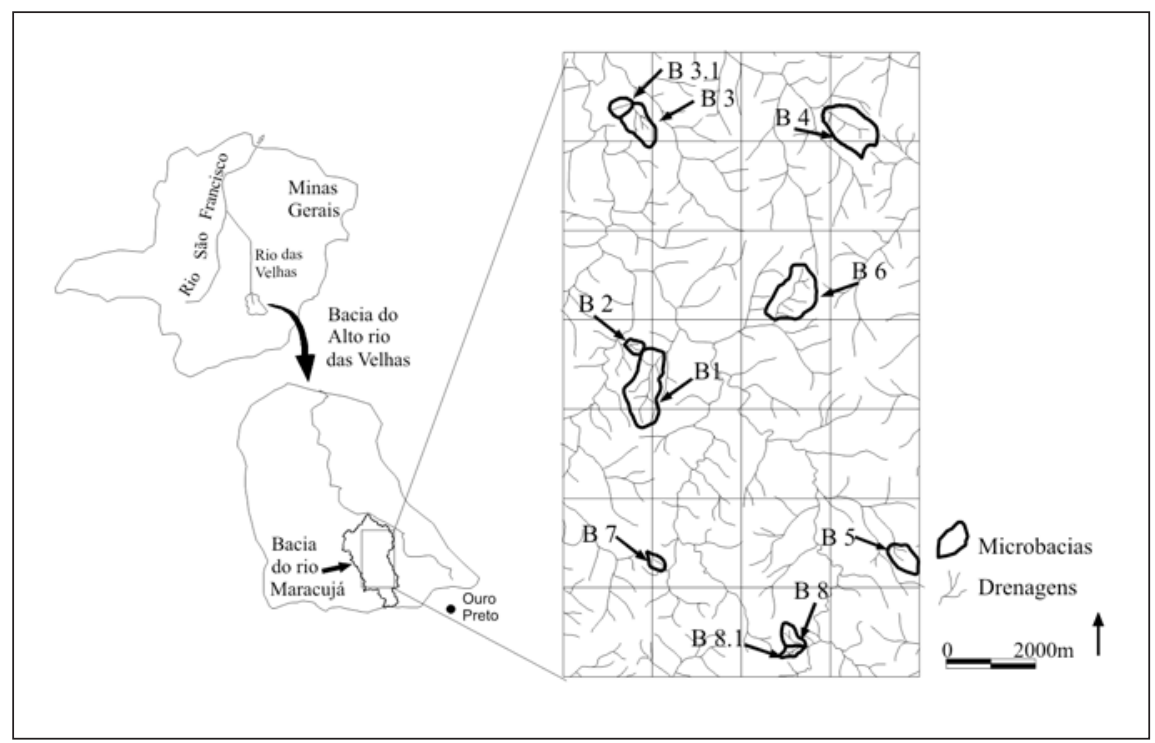

Figura 1 - Localização das dez microbacias onde foram instalados os vertedores portáteis (Modificado de Costa, 2005). 
Fernanda Martineli Costa et al.

nível de pedreiro, o prumo e a horizontalidade das ombreiras. A jusante dos vertedores, foram fixadas duas estacas de ferro como recurso adicional para garantir a verticalidade da placa (Figura 2). O volume do fluxo, relativamente pequeno, foi insuficiente para causar deformações nas chapas. Em alguns casos, acoplaram-se alças na porção superior do vertedor, para facilitar sua retirada quando necessário, por exemplo, para desassoreamento. Foi utilizada uma lona visando a vedar por completo a passagem de água pelas laterais e fundo do canal. Imediatamente abaixo da queda d’água, foram dispostos fragmentos de rocha de modo a impedir a erosão remontante até a base do vertedor. Em períodos de estiagem, não houve problema com vazamentos. Porém, com as chuvas, em três casos (B3, B8.1 e B4), iniciaram-se processos erosivos nas margens e foi necessário protegê-las, utilizando-se pedregulhos e madeira (Figura 3-C).

Deve-se considerar, ainda, a contração vertical da lâmina d'água ao adquirir velocidade em direção ao vertedor. Assim, a medida da carga (h), tomada por meio de uma régua fixada na parte montante do próprio vertedor, ou seja, tomada na seção de instalação, não corresponderia à altura real do nível d’água $(\mathrm{H})$, sendo recomendável medi-la a montante, numa distância que varia de 3 a 6 vezes o valor de h (Custodio \& Llamas, 1976; Delmée, 1983; Netto \& Alvarez, 1988; Porto, 2001). Há, ainda, a possibilidade de se determinar h na seção do vertedor e corrigir o valor segundo fórmula específica: $\mathrm{H}=7 / 6$ h (no caso de vertedores de parede delgada) (Daker, 1987).
As fórmulas de determinação da vazão utilizadas nesse trabalho, atentando que todos vertedores são delgados e de lâmina livre, foram (Custodio \& Llamas, 1976; Neves, 1982; Daker, 1987; Netto \& Alvarez, 1988; Feitosa \& Manoel Filho, 1997; Porto, 2001):

- Vertedor retangular - Fórmula de Francis: $Q=1,838(L-0,2 h) h^{3 / 2}$

- Vertedor triangular com ângulo de abertura de $90^{\circ}$ - Fórmula de Gourley e Crimp: $Q=1,32 h^{2,47}$

- Vertedor trapezoidal Cipoletti (trapézio isósceles com inclinação horizontal/vertical de $1 / 4): Q=1,86 L h^{3 / 2}$

Sendo $\mathrm{Q}\left(\mathrm{m}^{3} / \mathrm{s}\right)$ = vazão; $\mathrm{L}(\mathrm{m})=$ soleira (borda inferior da abertura); $\mathrm{h}(\mathrm{m})=$ carga hidráulica.
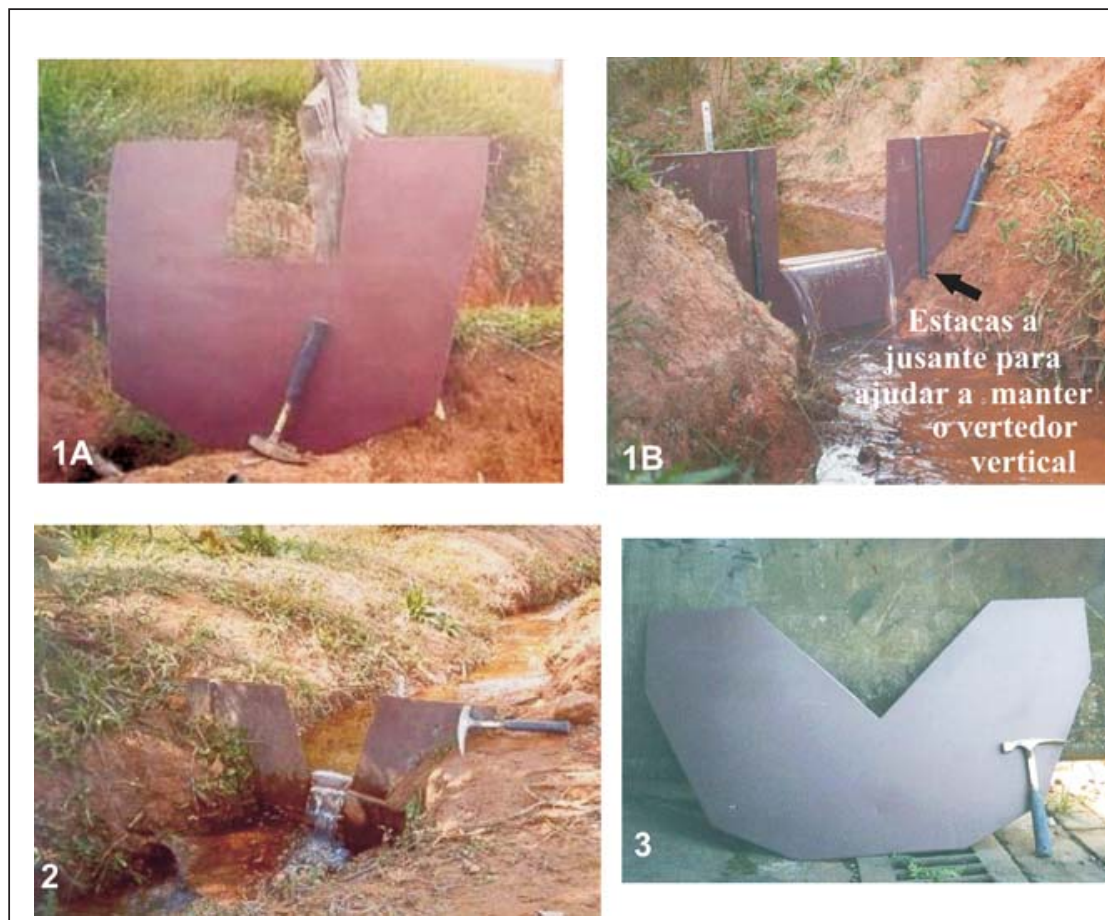

Figura 2 - Vertedores portáteis utilizados na pesquisa: 1A - vertedor retangular; 1B vertedor retangular instalado; $\mathbf{2}$ - vertedor trapezoidal Cipoletti; 3 - vertedor triangular (Modificado de Costa, 2005).

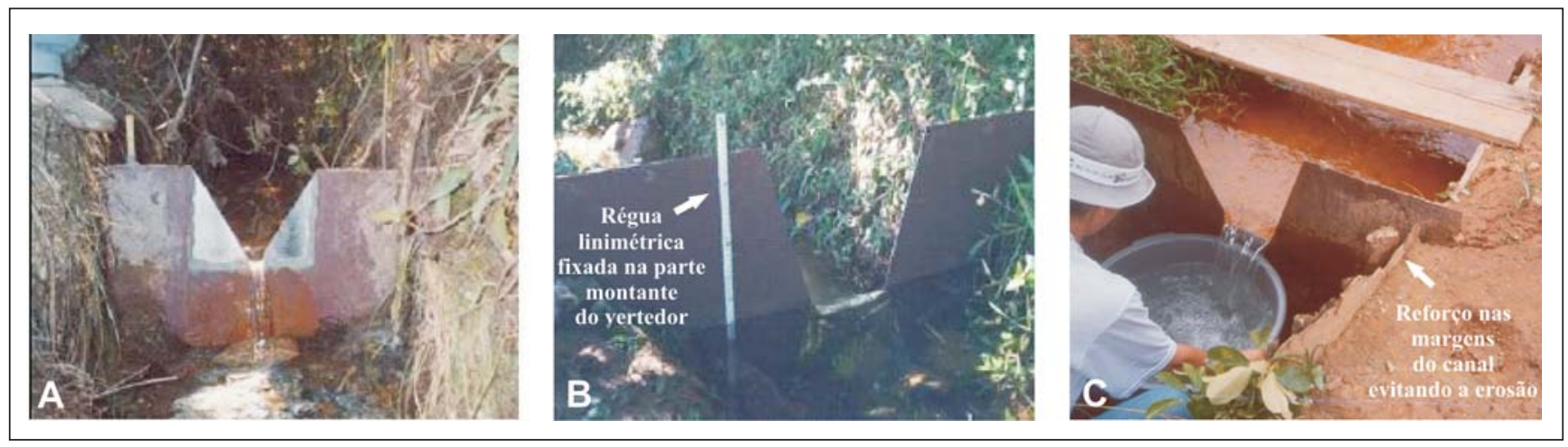

Figura 3 - A - Vertedor retangular adaptado para triangular (microbacia B8); B - Vertedor trapezoidal com régua linimétrica acoplada; C - Determinação da vazão pelo método volumétrico (Modificado de Costa, 2005). 


\section{Monitoramento fluviométrico nas microbacias}

Os vertedores portáteis cumpriram seus objetivos durante todo o monitoramento, exceto na microbacia B7, onde a quantidade de sedimento proveniente de uma voçoroca a montante (em especial nos eventos de chuva intensos) foi tal que, freqüentemente, causou o assoreamento ou, até mesmo, arrancou a placa do vertedor. Embora fosse esperado um grande aporte de sedimento e, nessas condições, vertedor não fosse o método mais indicado para monitorar a vazão (Custodio \& Llamas, 1976; Rantz, 1982), acreditava-se que algumas adaptações poderiam viabilizar seu uso, como as alças na parte superior para limpeza periódica do material assoreado (ABNT, 1995). Porém, nesse caso, não foram possíveis medições com um mínimo de confiabilidade e o monitoramento foi interrompido. Na microbacia com voçoroca B8.1, também ocorreu problema semelhante, mas em menor magnitude e o monitoramento pôde continuar (Costa \& Bacellar, 2007).

Foram necessários ajustes nos vertedores de duas microbacias (B8 e B1), cujas dimensões foram inicialmente superestimadas. Nesses casos, foram fei- tas adaptações, utilizando folhas de flandres e os vertedores retangulares foram modificados para triangulares (Costa, 2005) (Figura 3-A).

A leitura em campo do nível d’água (h) é simples, não sendo necessária mãode-obra especializada. No presente caso, uma régua linimétrica pouco deformável, de material plástico, foi acoplada na própria placa do vertedor (Figura 3 - B). O monitoramento foi feito diariamente por monitores (residentes próximo ao local) devidamente treinados. Fez-se um acompanhamento contínuo visando conferir os dados e, verificar a assiduidade dos monitores.

No período de estiagem, a leitura da vazão foi feita duas vezes ao dia: de manhã (por volta das 7h) e à tarde (aproximadamente $17 \mathrm{~h}$ ), com exceção das microbacias B5, B8 e B8.1, monitoradas apenas uma vez ao dia, devido à indisponibilidade por parte dos monitores. $\mathrm{Na}$ estação chuvosa (dez/2003 a mar/2004), foram tomadas de 3 a 4 medidas diárias em todas microbacias, com exceção da B5, onde foi possível tomar 2 medidas diárias nos meses de dezembro/2003 a janeiro/2004.

No intuito de verificar a consistência dos dados obtidos pelos vertedores, fizeram-se, paralelamente, medidas da vazão a partir do método volumétrico em diferentes estágios de fluxo (Figura 3 C). As correlações dos valores dos dois métodos foram excelentes, especialmente quando se utilizaram as medidas de carga na placa dos vertedores (h), com $\mathrm{R}^{\wedge} 2(\mathrm{R} \wedge 2$ = coeficiente de terminação) médio de 0,9735 (Costa, 2005). Como exemplo, apresentam-se os resultados na microbacia B6 (Figura 4). Dado que o método volumétrico é considerado de maior acurácia para pequenas vazões (Rantz, 1982), pode-se concluir que os vertedores portáteis são igualmente confiáveis. Os dados de vazão dos vertedores foram melhorados a partir das equações de correlação obtidas.

\section{Análise dos resultados}

A utilização das réguas linimétricas na própria chapa do vertedor (Figura 3-B), embora nem sempre recomendadas pelas normas, não causou erros consideráveis nos resultados. Os dados de vazão obtidos com h (altura d'água tomada na placa) mostraram melhor correlação com os dados obtidos com o método volumétrico que aqueles obtidos com a carga corrigida (H)(Figura 4). Pressupõe-se que isto se deva ao fato de a régua ter sido posicionada mais próxima

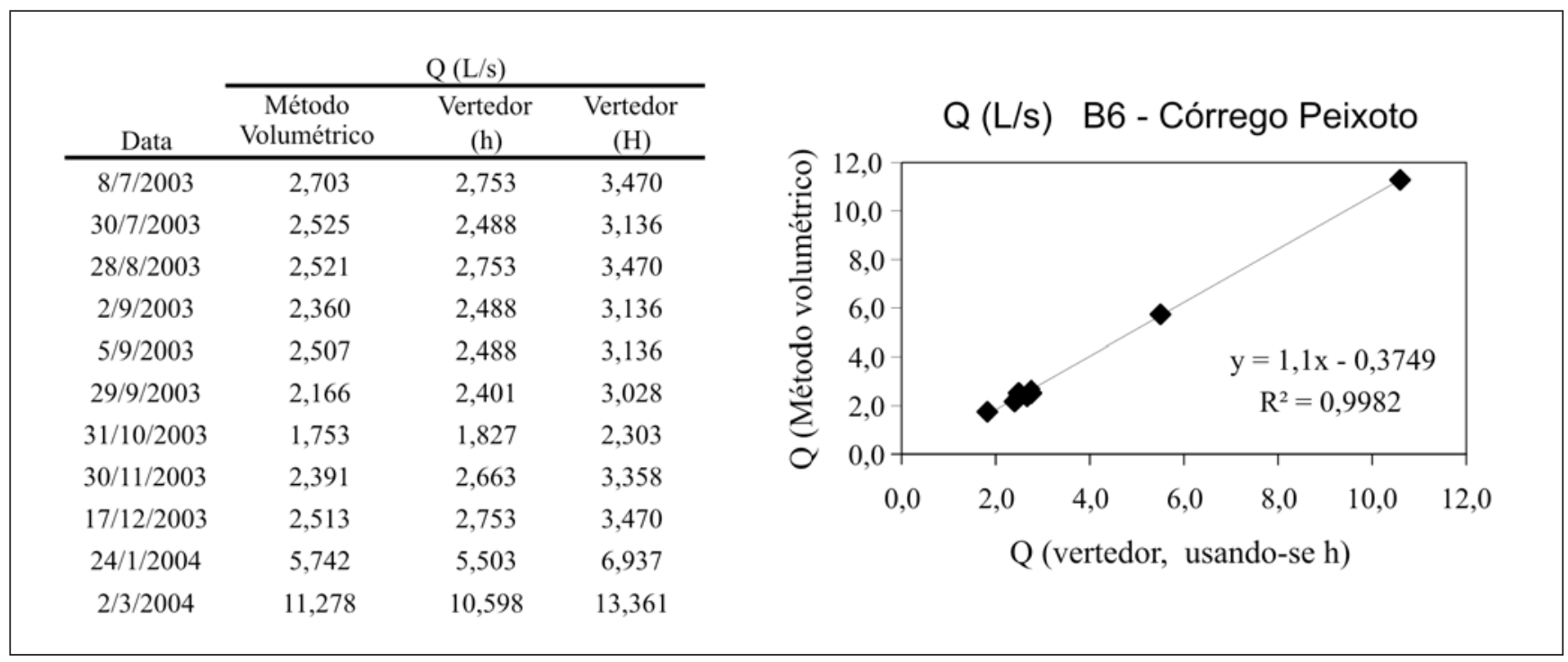

Figura 4 - Correlação entre as vazões obtidas pelo método volumétrico e pelo vertedor a partir de $\mathrm{h}$ (carga tomada na seção do vertedor) e H (carga corrigida por fórmula)(microbacia B6). 
à margem do canal, distante da zona de contração e, também, pela vazão ser relativamente pequena. De fato, nos modelos originais sugeridos pelo USGS (Rantz, 1982), a régua linimétrica é fixada no próprio vertedor, o mais distante possível da abertura deste.

Cabe expor que, em algumas ocasiões, picos de vazão não puderam ser medidos, quando houve o transbordamento do vertedor (pois existe uma vazão máxima possível de medição para cada vertedor) ou pelo fato de as medidas não terem sido contínuas, ou seja, tomadas de 2 a 4 vezes ao dia. Isto já era previsível, mas não afetou os resultados, uma vez que se almejava determinar as vazões em períodos de recessão. Além disso, cerca de 10 a 30\% de vazões de cheia não foram registradas devido ao transbordamento, o que não comprometeu o estudo. De fato, Silveira e Tucci (1998) afirmam que o não registro dessas vazões não prejudica a análise da disponibilidade hídrica por vazões mínimas. Ocorreram, também, situações raras em que a carga (h) foi inferior ao limite mínimo ou que a leitura não foi feita. Há, portanto, lacunas nas seqüências fluviométricas e o volume total de vazão é, assim, subestimado.

Depois de tratadas e calibradas, a partir das equações de correlação, as séries fluviométricas foram lançadas em hidrogramas, dos quais apresentam-se os referentes às microbacias B5 e B6 (Figura 5). Para facilitar a correlação entre bacias, recomenda-se utilizar vazão específica (vazão/área).

\section{Conclusões}

Os vertedores portáveis apresentaram-se inteiramente confiáveis na determinação de pequenas vazões, sendo uma opção segura, a baixo custo e com grande praticidade.

Em termos de custos, deve-se considerar essencialmente o material da placa e sua instalação: rápida e fácil, não sendo preciso desviar o curso d’água nem mão-de-obra especializada, sendo, portanto, uma opção mais barata. Adicionalmente, por serem móveis, podem ser reutilizados em diferentes projetos.

Como principal deficiência, podese apontar o não registro dos picos de vazão por extravasamento do vertedor. Em pequenas bacias, o tempo de elevação do hidrograma é rápido e, conseqüentemente, frente ao intervalo de leitura, muitas vezes os picos não são registrados. Em contrapartida, a descida e posteriormente, a recessão se dão a taxas mais lentas e, assim, podem ser mais facilmente registradas, o que de fato interessa, quando se pretende quantificar parâmetros relacionados ao fluxo de base. Especificamente nas microbacias analisadas, com áreas de até $1 \mathrm{~km}^{2}$, foi possível detectar, com segurança, a recessão do fluxo, mesmo com registros não-contínuos (Costa, 2005; Costa \& Bacellar 2007). Foi possível, inclusive, distinguir as diferenças do potencial hidrogeológico de cada microbacia por meio de diversos índices hidrológicos, como o coeficiente de recessão. Portanto, para análise de fluxo de base, a técnica do vertedor portátil apresenta-se válida, uma vez que não é primordial o conhecimento dos picos de cheia.

Vale destacar, novamente, a necessidade crescente de informações hidrológicas não só nas grandes bacias, mas, também, em microbacias como um importante suporte em projetos de preservação e de aproveitamento sustentável das fontes de água. Conclui-se que a técnica dos vertedores portáteis apresenta significativo potencial para contribuir nesse processo, uma vez que se constitui em uma alternativa prática, segura e viável economicamente.

\section{Agradecimentos}

Ao projeto "Instituto do Milênio: Água, uma visão mineral”, pelo financiamento; ao CNPq pela bolsa concedida e aos monitores de campo.

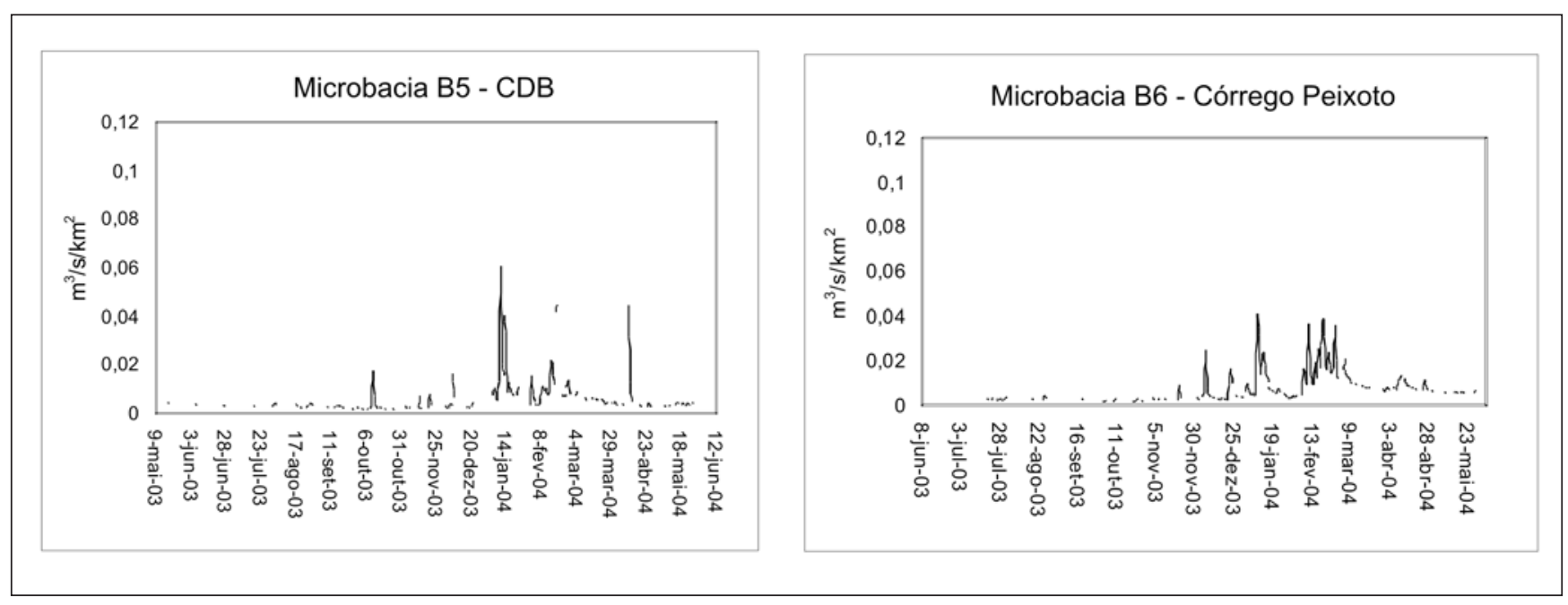

Figura 5 - Hidrogramas com vazão específica diária (B5 e B6). 
7. Referências

\section{bibliográficas}

ABNT - NBR 13403. Medição de vazão em efluentes líquidos e corpos receptores Escoamento livre, 1995. 7p.

COSTA, F. M. Análise por métodos hidrológicos e hidroquímicos de fatores condicionantes do potencial hídrico de bacias hidrográficas - Estudo de casos no Quadrilátero Ferrífero - MG. Ouro Preto: DEGEO, Universidade Federal de Ouro Preto, 2005. 147p. (Dissertação de mestrado).

COSTA, F.M., BACELLAR, L. de A.P. Análise da influência de algumas características das bacias hidrográficas nos componentes de deflúvio. In: SIMP. GEOLOGIA MG, XII, 2003. Ouro Preto. Anais... Ouro Preto: SBG, 2003. p.35.
COSTA, F.M., BACELLAR, L. de A.P. Analysis of the influence of gully erosion in the flow pattern of catchment streams, Southeastern Brazil. Catena, v.69, issue 3, p. 230-238, 2007.

CUSTODIO, E., LLAMAS, M.R. Hidrologia subterrânea. Barcelona: Ediciones Omega S.A., 1976. vol 2. 1157p

DAKER, A. Vertedores. In: Ed.F.Bastos,1987. cap.3, p 65-93. 316p.

DELMÉE, G.J. Manual de medição de vazão. São Paulo: Edgard Blücher Ltda, 1983. 476 p. NETTO, A., ALVAREZ, G.A. Vertedouros ou vertedores. In: Manual de Hidráulica.

NEVES, E.T. Curso de Hidráulica. (7.ed.) Rio de Janeiro: Editora Globo, 1982. 577p.

PORTO, R.M. Orifícios - tubos curtos - vertedores. In.: Hidráulica Básica. (2.ed.). São Carlos: EESC - USP, 2001. cap. 12, p. 381-391. 519p.

RANTZ, S.E. Measurement of stage and discharge. In: Measurement and Computation of Streamflow. Washington: Geological Survey Water-Supply paper 2175, 1982. v. 1. 284p. SILVEIRA, G.L., TUCCI, C.E.M. Monitoramento em pequenas bacias para estimativa de disponibilidade hídrica. Rev. Bras. Recursos Hídricos, v.3, p. 97-110, 1998.

\section{Descubra as muitas informações da:}

\section{Geologia, Mineração, Metalurgia \& Materiais} e Engenharia Civil.
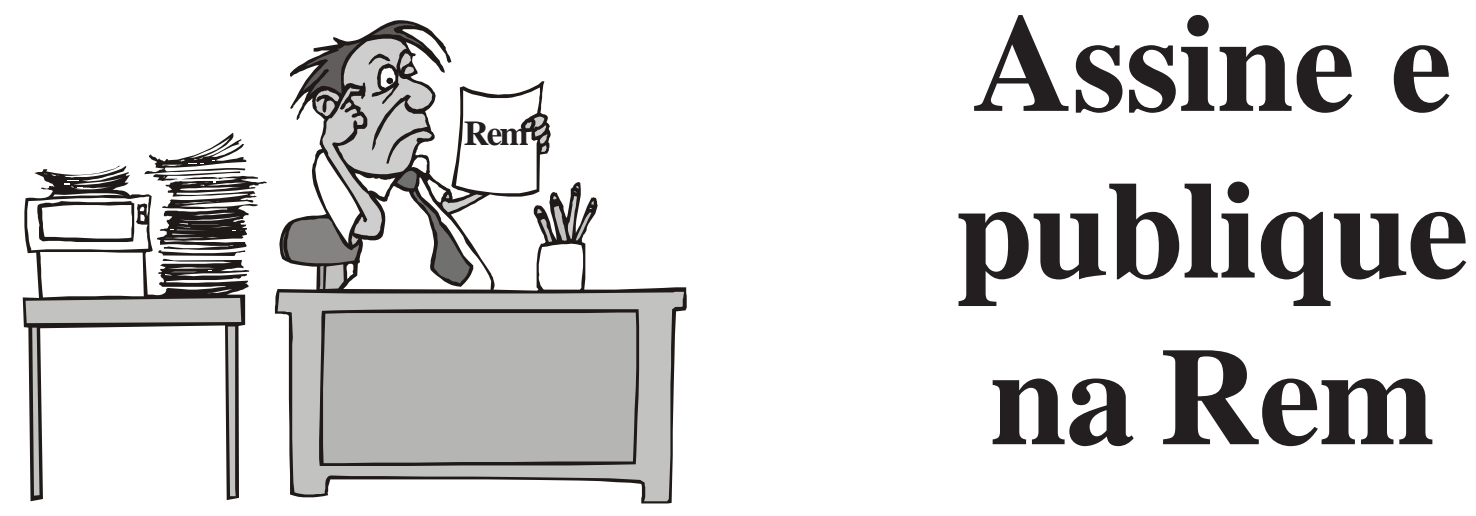

Conheça o nosso novo site: WWW.rem.com.br 